\title{
Le portail des cabinets médicaux
}
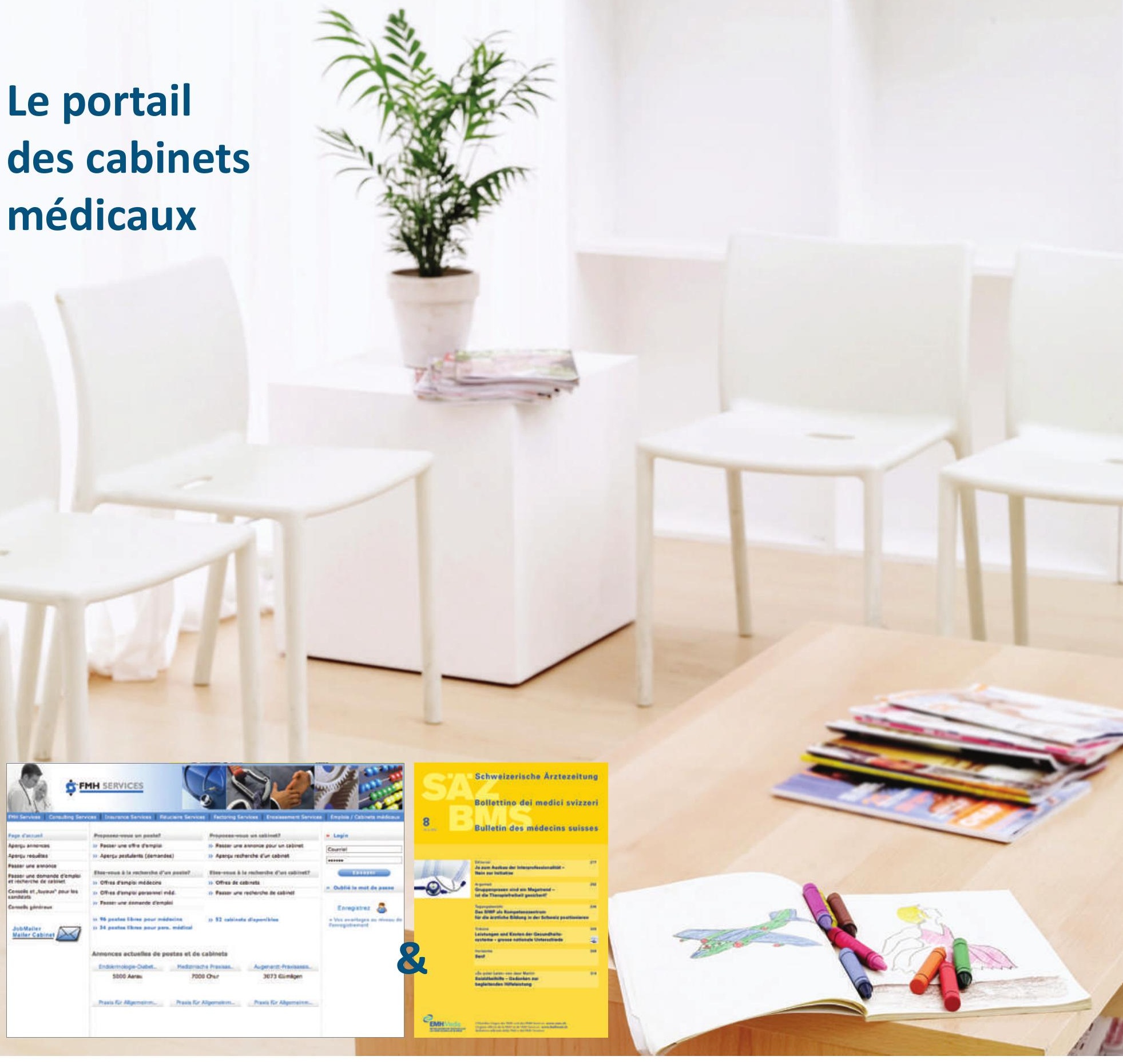

\section{WWW.FMHPRAX.CH}

\section{Proposer un cabinet}

- Saisie, mutation et gestion simples des annonces

- Optimisation des coûts grâce à la publication combinée web (www.fmhprax.ch) - impression (Bulletin des médecins suisses)

- Offre chiffrée

- Mise en ligne de photos pour une présentation optimale du cabinet

Rechercher un cabinet

- Saisie, mutation et gestion simples des recherches de cabinets

- Optimisation des coûts grâce à la publication combinée web (www.fmhprax.ch) - impression (Bulletin des médecins suisses)

- Recherche chiffrée

- Nouvelles offres de cabinets gratuites par e-mail (Mailer Cabinet)

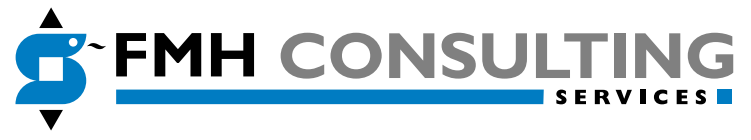

FMH Consulting Services AG Burghöhe 1, 6208 Oberkirch tél. 0419250077 - fax 0419210586 mail@fmhjob.ch -www.fmhservices.ch 